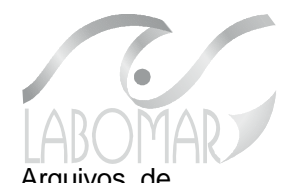

Arquivos de Ciências do Mar

\section{IMPACTOS AMBIENTAIS DOS CULTIVOS DE CAMARÕES MARINHOS NO NORDESTE DO BRASIL}

\author{
Environmental impacts of shrimp farming in the \\ Brazilian Northeast
}

Tereza Cristina Vasconcelos Gesteira ${ }^{1}$, Melquíades Pinto Paiva $^{2}$

\begin{abstract}
RESUMO
Com a estabilização da pesca em escala mundial, a aqüicultura surge como a mais importante alternativa. Entre os recursos marinhos cultivados, os camarões peneídeos representam o grupo mais promissor no Brasil. Após seu início na década de 70 do século passado, a carcinicultura marinha brasileira, passou por uma série de crises, até atingir o patamar do sétimo maior produtor mundial e líder da América Latina, em 2002, com uma produção de 60.128 t. A Região Nordeste brasileira é responsável por $96,5 \%$ dessa produção, quando se considera toda a cadeia produtiva. O tema carcinicultura tem sucitado controvertidos debates entre ambientalistas e a classe produtora. Como principiais danos, a carcinicultura causaria a destruição de manguezais, salinização de aqüíferos, poluição das áreas adjacentes pelos efluentes das fazendas, perda da biodiversidade durante a coleta de pós-larvas e escape de espécies exóticas para o ambiente natural. Todos estes pontos podem ser mitigados pela as boas práticas de cultivo, e alguns deles já não atingem os carcinicultores brasileiros, tais como a construção de viveiros em áreas de mangue e coleta de pós-larvas silvestres. É indiscutível que continuidade deste importante agronegócio depende da proteção do meio ambiente, ao qual está intimamente ligado.
\end{abstract}

Palavras-chaves: carcinicultura, meio ambiente, benefícios sócio-econômicos.

With fisheries catches stable at the global level, aquaculture has become the most important alternative. Among all farmed marine organisms, penaied shrimp are the most promising group for Brazilian mariculture. After the beginning of shrimp farming in the 1970's in the country, the Brazilian industry has gone through a series of crises until becoming the $7^{\text {th }}$ largest world producer of farm-reared shrimp in 2002. In that year, the country harvested 60,128 Mt of marine shrimp. The Northeastern region accounted for $96.5 \%$ of Brazil's total production. Shrimp farming has led to controversial debates between environmentalist and farmers. The major impacts of this activity are the destruction of mangrove forest, the salinization of aquifers, the polluition of nearby areas by farm effluents, the rediction in biodiversity during the catch of wild post-larvae and the escape of exotic species into the natural environment. All these impacts can be mitigated though good farminf, as some of them are not relevant to shrimp culture. The construction of ponds in mangrove-covered lands and the collection of wild post-larvae are pratices that are no longer part of this activity. Is is clear that the survival of the farming business relies on the protection of the environment to which it is intimately linked.

Key words: shrimp culture, environment, social and economic benefits.

\footnotetext{
${ }^{1}$ Instituto de Ciências do Mar, Universidade Federal do Ceará, Av. daAbolição,3207-Fortaleza, CE60165-081.E-mail:<gecmar@labomar.ufc.br> ${ }^{2}$ Departamento de Biologia Marinha da Universidade Federal do Rio de Janeiro, Cidade Universitária, RJ - CEP 21944-970. Endereço para correspondência: Rua Baronesa de Poconé, 71/701, Rio de Janeiro, RJ. 22471-270. E-mail: <mappaiva@uol.com.br>
} 
Em escala mundial, a produção de pescado se encontra estabilizada ou mesmo em declínio, quando consideramos apenas a exploração dos estoques naturais, por causa da sobrepesca, alterações de áreas essenciais para a renovação das biotas, e a poluição dos pesqueiros. Isto vem ocorrendo tanto nas águas interiores quanto nas águas estuarinas/marinhas.

Existem poucas possibilidades da descoberta e exploração de novas áreas de pesca ou da incorporação de recursos ainda não explorados. No sistema da produção pesqueira, as melhores alternativas de aumento da oferta de pescado se encontram na redução dos desperdícios do processamento industrial e obtenção de subprodutos;noaproveitamentode pequenos estoques pela pesca artesanal; com a utilização de faunas acompanhantes das atuais pescarias; $\mathrm{e}$, finalmente, de forma proeminente, com o desenvolvimento da aqüicultura.

Com a concentração e crescimento da população humana, a coleta e a caça/pesca mostraram tendências decrescentes, não mais atendendo o incremento das demandas. A solução então encontrada foi a domesticação de plantas e animais, dando origem e expansão às atividades agrícolas e pecuárias. Adotando-seeste procedimento, a aqüiculturaéa etapa superior da explotação dos recursos vivos das águas interiores e estuarinas/marinhas.

Recentes estatísticas nacionais evidenciam que as pescarias continental e oceânica mostram tendências de recuperação das respectivas produções, mas não comparáveis com o crescimento da aqüicultura, que é o segmento dinâmico da produção de pescado no Brasil (Tabela I).

O desenvolvimento da maricultura, em nosso país, enfrenta os naturais entraves de natureza técnica e econômica, agravados pela impossibilidade legal da apropriação privada da faixa costeira mais próxima da zona entre-marés e dos espaços estuarinos / marinhos adjacentes.

É bem antiga a produção de ostras e mexilhões, em pequena escala, resultante de cultivo em baías do Sudeste/Sul do Brasil. Em nível industrial, os culti-
Tabela I - Evolução da produção de pescado no Brasil, segundo suas origens, nos anos de $1994-2002$.

\begin{tabular}{cccccc}
\hline Anos & $\begin{array}{c}\text { Pescas } \\
\text { interiores }\end{array}$ & $\begin{array}{c}\text { Pescas } \\
\text { costeiras }\end{array}$ & $\begin{array}{c}\text { Pescas } \\
\text { oceânicas }\end{array}$ & Aqüicultura & $\begin{array}{c}\text { Produção } \\
\text { total }\end{array}$ \\
\hline \multicolumn{5}{c}{ Produção de pescado $\left(10^{3}\right.$ t) } & 32,00 \\
\hline 1994 & 203,22 & 469,02 & 24,23 & 728,47 \\
1995 & 193,04 & 391,41 & 22,26 & 46,20 & 652,91 \\
1996 & 210,28 & 394,56 & 27,62 & 60,72 & 693,18 \\
1997 & 178,87 & 433,09 & 52,63 & 87,67 & 752,26 \\
1998 & 173,00 & 419,00 & 40,00 & 93,00 & 725,00 \\
1999 & 158,90 & 403,00 & 44,00 & 139,10 & 745,00 \\
2000 & 238,00 & 406,00 & 54,00 & 172,00 & 860,00 \\
2001 & 223,00 & 410,00 & 62,00 & 204,00 & 899,00 \\
2002 & 230,00 & 420,00 & 75,00 & 260,00 & 985,00 \\
\hline \multicolumn{5}{c}{ Produção de pescado (\%) } \\
\hline 1994 & 27,90 & 64,38 & 3,33 & 4,39 & 100,00 \\
1995 & 27,57 & 59,95 & 3,41 & 7,08 & 100,00 \\
1996 & 30,34 & 56,92 & 3,98 & 8,76 & 100,00 \\
1997 & 24,43 & 59,14 & 4,46 & 11,97 & 100,00 \\
1998 & 23,86 & 57,79 & 5,52 & 12,83 & 100,00 \\
1999 & 21,33 & 54,09 & 5,91 & 18,67 & 100,00 \\
2000 & 26,51 & 47,21 & 6,28 & 20,00 & 100,00 \\
2001 & 24,81 & 45,61 & 6,90 & 22,69 & 100,00 \\
2002 & 23,35 & 42,64 & 7,61 & 26,40 & 100,00 \\
\hline
\end{tabular}

Fonte: Instituto Brasileiro do Meio Ambiente e dos Recursos Naturais Renováveis (IBAMA).

vos têm-se restringido aos camarões peneídeos, com espécies exóticas, ocupando áreas adjacentes aos manguezais e/ou antigas salinas, principalmente na região nordestina, com destaque para os Estados do Rio Grande do Norte e Ceará (Tabela II; Figura 1).

A carcinicultura marinha brasileira passou por várias etapas de evolução desde a sua implantação nos anos 70 do século passado, com a criação do Projeto Camarão do Banco de Desenvolvimento do Rio Grande do NorteS/A, posteriormente denominado Projeto Camarão da Empresa de Pesquisa Agropecuária do Rio Grande do Norte S/A-EMPARN (Paiva, 1997). Era uma alternativa de resolver a séria crise pela qual passava o setor salineiro potiguar.

Naquela mesma década, também foram iniciadas pesquisas nos Estados de Santa Catarina e Rio Grande doSul, que resultaram na obtenção da desova em ambiente controlado e na produção das primeiras

Tabela II - Produção brasileira de camarões marinhos cultivados, por Estados, nos anos de 1996/2002.

\begin{tabular}{|c|c|c|c|c|c|c|c|c|c|c|c|c|c|c|c|c|}
\hline \multirow[t]{2}{*}{ Ano } & \multicolumn{8}{|c|}{ Produção em peso inteiro } & \multicolumn{6}{|c|}{ Peso inteiro $(t)$} & \multicolumn{2}{|c|}{ Totais } \\
\hline & $\mathrm{MA}$ & P1 & E & $\mathrm{kN}$ & 10 & $P E$ & Al. & $\mathrm{SHE}$ & UA & PA & ES & sp & $P R$ & $x$ & Nondeate & Itrapil \\
\hline 1996 & 130,0 & $\sin , 0$ & 21,0 & $1.120,0$ & 220,0 & 25 & . & - & 1.4600 & 180 & - & $10 \Omega$ & - & 29,0 & $3,315,5$ & $3.364, i$ \\
\hline 1997 & 1200 & $24 \mathbf{4}, 0$ & 2620 & $1.152,0$ & 2270 & 630 & - & 2,0 & 1ASOR & 300 & - & 210 & $30 \Omega$ & $12 \pi$ & $3.520,2$ & 3.61:30 \\
\hline 1998 & 60,0 & $\triangle 04,0$ & 1.9860 & $1.737,0$ & 496,0 & 5310 & - & 2,0 & $1.9 m 0$ & 30,0 & - & 210 & 30,0 & 150 & $7.223,0$ & 7,3240 \\
\hline 1949 & 1150 & 1917,5 & 6.2090 & $1.568,0$ & $1.058,0$ & 17120 & - & 96,0 & 2.8000 & 1300 & - & 115,0 & 35,0 & 289,0 & $15.485,5$ & 16.063 .5 \\
\hline 2000 & 160,0 & $1.092,0$ & $4.960,0$ & $7.000,0$ & $1.300,0$ & 2630,0 & 500 & 188,0 & 6.90000 & 1400 & - & 40,0 & $1,50,0$ & 400,0 & $24.200,0$ & $25,000,0$ \\
\hline 2001 & 452,0 & 2.1120 & $11.333,0$ & $9.061,0$ & 2.1240 & 43110 & 40,0 & $1.302,0$ & 6.8400 & 1500 & 4120 & 50,0 & 100,0 & 173,0 & $37.575,0$ & 40,00000 \\
\hline 2002 & 727,0 & $2.818,0$ & 10.3530 & $18.800,0$ & 3.018 .0 & 6792.0 & 1000 & $1.765,0$ & 40220 & $78 \rho$ & 258,0 & - & 140,0 & 1650,0 & 55.023 .0 & $\omega 0.128,0$ \\
\hline
\end{tabular}

Fonte: Associação Brasileira dos Criadores de Camarão- ABCC; Instituto Brasileiro de Recursos Renováveis - IBAMA; Purina do Brasil. 


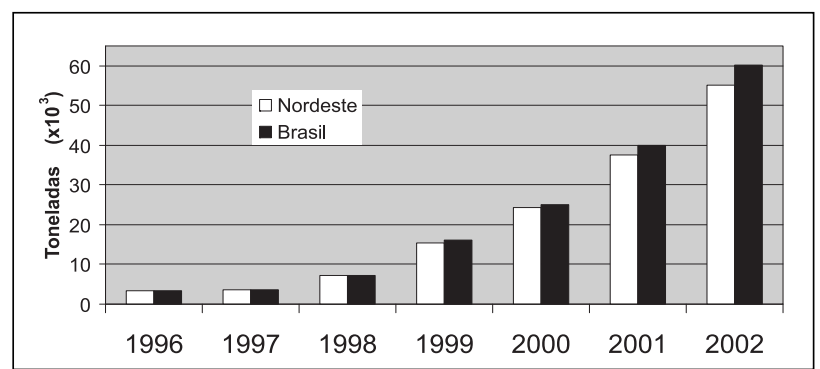

Figura 1 - Produção cultivada de camarões marinhos da Região Nordeste e do Brasil, nos anos de 1996 a 2002.

pós-larvas em laboratório, da espécie Farfantepenaeus paulensis (Pérez Farfante, 1967).

Como parte do Projeto Camarão, foi introduzida, a partir de 1977, a espécie Marsupenaeus japonicus (Bate, 1888), com vistas à produção comercial em cativeiro, de forma extensiva. Os resultados iniciais estimularam a expansão dos cultivos, alcançando outros estados, tais como Bahia, Ceará e Piauí (Brasil/DPA, 2001).

Devido ao insucesso dos cultivos do Marsupenaeus japonicus (de Mar, 1879) no Nordeste do Brasil, resultante das condições ambientais pouco favoráveis e de fatores tecnológicos, os carcinicultores regionais voltaram seus esforços no sentido de domesticar as espécies nativas Litopenaeus schmitti (Burkenroad, 1936), Farfantepenaeus subtilis (Pérez Farfante, 1967), Farfantepenaeus brasiliensis (Latreille, 1817) e Farfantepenaeus paulensis (Pérez Farfante, 1967). Ao mesmo tempo, alguns empresários introduziram outras espécies exóticas, tais como Penaeus monodon (Fabricius, 1798), Litopenaeus stylirostris (Stimpson, 1874) e Litopenaeus penicillatus (Alcock, 1905).

Embora o trabalho de domesticação das espécies nativas tenha alcançado êxito no que diz respeito às reproduções e larvicultura, principalmente com a espécie Farfantepenaeus subtilis, a fase de engorda deixou muito a desejar devido ao pouco conhecimento dos requerimentos nutritivos das espécies, com baixa produtividade dos cultivos, tornando a atividade pouco atrativa sob o ponto de vista econômico.

Em verdade, o ciclo de expansão da carcinicultura brasileira se iniciou em meados da década de 90 do século passado, quando foi introduzida a espécie exótica Litopenaeus vannamei (Boone, 1931), originária do Pacífico - do golfo da Califórnia ao norte do Peru. Daí em diante, foi marcante o crescimento da carcinicultura nacional, quando foram dominadas e aperfeiçoadas as técnicas de reprodução, larvicultura e engorda dessa espécie.

Como decorrência, os projetos de construção das fazendas se tornaram de melhor qualidade sob os pontos de vista estrutural e econômico.Por outrolado, a mão-de-obra passou a ser mais qualificada e as empresas contaram com técnicos especializados. Vale salientar a melhoria de qualidade das rações ofertadas no mercado e a maior disponibilidade de pós-larvas, com o aumento do número de larviculturas. Estes fatos e ações possibilitaram a intensificação dos cultivos e garantiram uma maior produtividade.

Agora, o Brasil ocupa a sétima posição entre os maiores produtores mundiais de camarão cultivado, com uma produção de $60.128 \mathrm{t}$ no ano de 2002 , sendo 96.5\% (58.010 t) provenientes da Região Nordeste, tendo como maior produtor o Estado do Rio Grande do Norte (18.500 t), seguido pelo Estado do Ceará (16.383 t) - Tabela II, que é o líder mundial em produtividade dos cultivos (Rocha \& Rodrigues, 2003).

Ocrescimentodesteimportante agronegóciotrouxe para a região mais pobre do Brasil, e a menos contemplada por programas governamentais de desenvolvimento, uma série de benefícios em termos de geração de empregos e de divisas, com a exportação do camarão para os mercados externos. Considerando-se os empregos diretos e indiretos gerados por esta atividade (3,75/ha), chega-se a 38.576 postos na Região Nordeste do Brasil (Sampaio \& Costa, 2003).

Otema "carcinicultura" tem levado a controvertidas discussões entre ambientalistas e classe produtora, sobre os impactos de sua pratica no Brasil. Usamse como argumentos exemplos oriundos do sudeste da Ásia ou do Equador, onde a má gestão de produtores e/ou normas ambientais pouco rígidas causaram sérios problemas ecológicos.

Entre os principais danos resultantes da pratica da carcinicultura, apontados pelos ambientalistas, alinham-se os seguintes: destruição de manguezais, salinização de aquíferos, poluição das áreas adjacentes pelos efluentes das fazendas, perda da biodiversidade e o escape de espécies exóticas para o ambiente natural.

No Brasil as fazendas de carcinicultura foram construídas em antigos viveiros de peixes estuarinos, salinas desativadas, apicuns e litoral superior, atrás dos mangues; nos Estados do Ceará e Piauí, predominam as áreas de apicuns; no Rio Grande do Norte e Paraíba, em grande maioria, ocupam áreas de antigas salinas e viveiros de peixes; na Bahia e em Pernambuco, se localizam em áreas do litoral superior. No Brasil e em sua região Nordeste, os totais das áreas de cultivo de camarões marinhos já ultrapassam 10.000 ha (Tabela III; Figura 2).

De um modo geral, pode-se dizer que não existem registros, nos órgãos ambientais, sobre a quantificação de áreas de mangue desmatadas para a construção de viveiros de camarão. Tomando-se por base a área de manguezais do Brasil que, segundo Kjerfve \& Lacerda (1993) é de 1.380 .000 ha, e a área total (11.016 ha) das fazendas de carcinicultura construídas até 2002 (Tabela III) - caso todos os em- 
Tabela III - Áreas de cultivo de camarões marinhos na região Nordeste e no Brasil, nos anos de 1996 a 2002.

\begin{tabular}{l|c|c}
\hline \multirow{2}{*}{ Ano } & \multicolumn{2}{|c}{ Área (ha) } \\
\cline { 2 - 3 } & Nordeste & Brasil \\
\hline 1996 & 2.935 & 3.026 \\
1997 & 3.385 & 3.546 \\
1998 & 4.133 & 4.320 \\
1999 & 4.940 & 5.200 \\
2000 & 5.890 & 6.250 \\
2001 & 7.704 & 8.500 \\
2001 & 10.287 & 11.016 \\
\hline
\end{tabular}

Fonte: Associação Brasileira de Cultivadores de Camarão ABCC, Purina do Brasil.

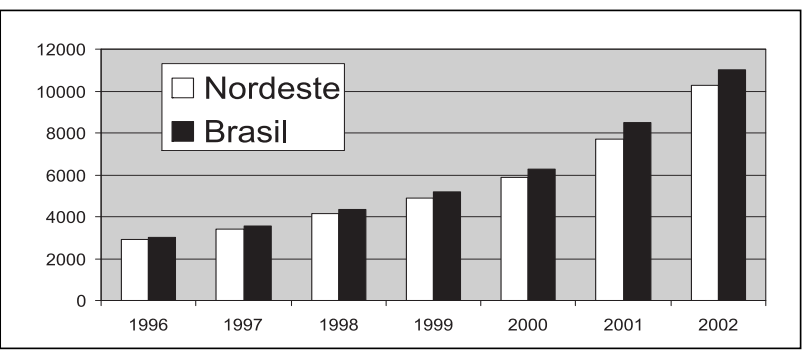

Figura 2 - Áreas de cultivo de camarões marinhos na Região Nordeste e no Brasil, nos anos de 1996 a 2002.

preendimentos tivessem sido construídos nesse ecossistema, o que não corresponde à realidade - teria sido desmatado $0,80 \%$ das áreas de mangue.

Aqui não se está justificando ou pontificando a destruição dos manguezais (áreas de preservação permanente), mas apenas chamando-se a atenção para a carência de dados que possam embasar uma discussão séria. Portanto, torna-se necessário o apoio governamental e das agências de desenvolvimento, para que sejam feitos estudos através do sensoriamento remoto (SR) e do sistema de informação geográfica (GIS), para mapear as áreas onde estão instaladas as fazendas de cultivo. A partir dos dados obtidos, será possível quantificar as áreas desmatadas e monitorar os projetos de carcinicultura.

Dois pontos podem ser destacados quando o assunto é a construção dos projetos de cultivo de camarões em manguezais: (a) a qualidade do solo, que é comprovadamente inadequada, devido à sua acidez e à grande quantidade de matéria orgânica; (b) a consistência do solo, que aumenta o custo da construção dos viveiros e dificulta o processo de drenagem (Boyd, 1998). A resolução 312, de 10 de outubro de 2002, do Conselho Nacional do Meio Ambiente CONAMA, dispõe sobre o licenciamento ambiental dos empreendimentos de carcinicultura na zona costeira do Brasil.
Acerca da salinização dos aquíferos subterrâneos, devido à percolação dos viveiros de cultivo, este problema pode ser resolvido através da melhor compactação dos solos, taludes e diques. A salinização dos aquíferos é bem menor em solos argilosos do que naqueles arenosos.

A quantidade e qualidade dos efluentes de uma fazenda de carcinicultura depende do seu tamanho, forma de cultivo (extensivo, semi-intensivo e intensivo) e das técnicas de manejo empregadas. A água drenada durante as rotinas de renovação tende a ser compatível com aquela existente na massa d'água receptora, caso exista um monitoramento criterioso durante o cultivo. Contudo, os problemas podem se agravar com a passagem do sistema semi-intensivo para o intensivo, resultando no aumento da quantidade de fertilizantes e ração utilizados, levando à deterioração dos efluentes.

Os riscos decorrentes das descargas de efluentes vão desde o incremento da demanda bioquímica de oxigênio (DBO), reduzindo o oxigênio da água receptora, até a eutrofização, por causa da grande quantidade de fósforo e nitrogênio de rações ricas em proteínas e de fertilizantes. Dependendodonúmerode fazendas em uma área, estes riscos aumentam, podendo ultrapassar a capacidade de suporte do ecossistema adjacente. A localização de uma fazenda, especialmente em relação à taxa de fluxo da água receptora, é um ponto crítico para o sucesso da carcinicultura (Preston et al., 2001; Boyd \& Green, 2002).

Estudos de avaliação da qualidade da água, em algumas fazendas de carcinicultura do Nordeste do Brasil, concluíram que não havia diferenças significativas entre as águas de abastecimento e de drenagem dos viveiros, porém os níveis de fósforo foram considerados elevados (Maia et al., 2003).

Algumas medidas mitigadoras podem ser adotadas, no sentidode reduzir osimpactos ambientais dos efluentes das fazendas de camarão: (a) redução das trocas de água, podendo chegar a zero; (b) uso de bio-filtros (macroalgas e/ou moluscos) nos canais de drenagem; (c) uso de bacias de sedimentação, que é a estratégia ideal e cuja construção é atualmente exigida pelos órgãos ambientais brasileiros.

Ainda com respeito aos efluentes, os ambientalistas chamam a atenção para os produtos químicos usados durante as operações de cultivo. Na carcinicultura brasileira são empregados produtos calcários, hipoclorito e fertilizantes químicos. De um modo geral, estes produtos não constituem ameaças ao meio ambiente, quando bem dosados.

Um ponto relevante diz respeito ao uso de antibióticos nos cultivos. Durante anos estes fármacos, principalmente a oxitetraciclina, foram adicionados às rações para a prevenção de enfermidades bacte- 
rianas. Agora, esta prática é cada vez mais rara. Os riscos da utilização indiscriminada dos antibióticos vão desde a formação de cepas de bactérias altamente resistentes até a graves problemas para a saúde humana. Devido a exigências dos países importadores, o emprego de antibióticos na carcinicultura brasileira está cada vez mais criteriosa.

Em alguns países, como Equador e Bangladesh, a criação de camarões marinhos é dependente da coleta de pós-larvas em ambiente natural. A grande preocupação resultante desta prática está relacionada com a redução dos estoques nativos e os impactos sobre a biodiversidade, uma vez que junto com as capturas vêm outras espécies, que são descartadas.

No Brasil, com o domínio da reprodução das espécies nativas em cativeiroe, posteriormente, com o cultivo da espécie exótica Litopenaeus vannamei, as fazendas são totalmente independentes das coletas de pós-larvas silvestres. Aqui existem 28 laboratórios de larvicultura, com previsão de mais sete até o final de 2003. A produção nacional de pós-larvas foi de 11.441.000, no ano de 2002 (Guerrelhas, 2003).

Os escapes de uma espécie exótica para a natureza constituem poluição biológica. Outro grande problema tem sido a introdução de patógenos (Tabela IV), que podem afetar populações nativas em áreas adjacentes às fazendas. Por este motivo, torna-se necessário que as larviculturas brasileiras trabalhem no sentido de produzir estoques livres e/ou resistentes a patógenos específicos.

Uma atividade como a do cultivo de camarão marinho, que vem crescendo de forma marcante e que já representa $66 \%$ dos crustáceos cultivados em todo o mundo (Tacon, 2002), deve buscar a sustentabilidade, com a identificação dos seus erros, troca de informações e aperfeiçoamento das técnicas de manejo, procurando a redução de custos. É indiscutível que a continuidade deste importante agronegócio depende da proteção do meio ambiente, ao qual está intimamente ligado. A natureza sempre cobra dos homens os desmandos contra ela praticados.

Tabela IV - Enfermidades registradas em fazendas de carcinicultura e larviculturas, em operação no Nordeste do Brasil.

\begin{tabular}{|c|c|c|c|}
\hline Enfermidade & Agente etiologico & Espécies infectadas & Referẻncias \\
\hline $\begin{array}{l}\text { Enfermidade de } \\
\text { Baculovirus - BP }\end{array}$ & Baculovirus penaei & 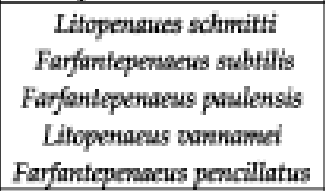 & $\begin{array}{c}\text { Bueno, et al. , 1989; } \\
\text { Bueno, ef al. , 1990; } \\
\text { Bueno, 1991; }\end{array}$ \\
\hline $\begin{array}{l}\text { Enfermidades do } \\
\text { Baculovirus tipo } \\
\text { Penaeus - MBV }\end{array}$ & $\begin{array}{l}\text { Baculootirus tipo } \\
\text { monodon }\end{array}$ & Penocus monadon & $\begin{array}{l}\text { Lightner \& Redman, } \\
\qquad 1992 ; \\
\text { Lightner, } 1996 .\end{array}$ \\
\hline $\begin{array}{l}\text { Infecçado } \\
\text { Hipodermal e } \\
\text { Necrose } \\
\text { Hematopoietica } \\
\text { IHHN, } \\
\text { Sindrome do } \\
\text { Nanismo }\end{array}$ & Parvovirus & $\begin{array}{l}\text { Lifoperiaeus zannamel } \\
\text { Penarws monadon }\end{array}$ & $\begin{array}{c}\text { Bueno, 1991; } \\
\text { Lightner, 1996; } \\
\text { Gesteira \& Andrade, } \\
2002 .\end{array}$ \\
\hline $\begin{array}{l}\text { Sindrome de } \\
\text { Taura -TS }\end{array}$ & Picornavirus & Litopennacus nonnamei & $\begin{array}{l}\text { Brock et al., 1995; } \\
\text { Hansson et al., 1999 } \\
\text { Andrade \& Gesteira, } \\
\text { 2000; } \\
\text { Gesteira \& Andrade, } \\
\text { 2002. }\end{array}$ \\
\hline $\begin{array}{l}\text { Heptopancreatite } \\
\text { Viral - HPV }\end{array}$ & $\begin{array}{c}\text { Parooceinus } \\
\text { Hepatopancreático }\end{array}$ & 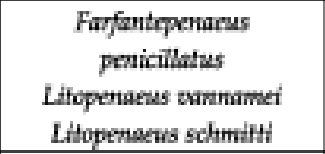 & $\begin{array}{l}\text { Bueno et al. 1995; } \\
\text { Gesteira \& Andrade, } \\
2002 .\end{array}$ \\
\hline $\begin{array}{l}\text { Hepatopancreatite } \\
\text { Necrosante NHP }\end{array}$ & $\begin{array}{c}\text { alpha- } \\
\text { protecobactéria }\end{array}$ & Lifopenaews zamnamei & $\begin{array}{l}\text { Gesteira \& Andrade, } \\
\text { 2002; } \\
\text { Pantoja \& Lightner, } \\
2003 .\end{array}$ \\
\hline Vibricse & $\begin{array}{c}\text { Vibrio alginolyticus } \\
\text { V. fluvialis } \\
\text { Vilorio spp }\end{array}$ & Lifopernaews tumnamet & Vieira et al., 2000. \\
\hline
\end{tabular}




\section{REFERÊNCIAS BILIOGRÁFICAS}

Andrade, T.P. \& Gesteira, T. C. V. Uso das técnicas de hibridação in situ e histológica para diagnóstico da Sindrome de Taura em camarões cultivados na Região Leste do Estado do Ceará. Resumos do Encontro de Iniciação à Pesquisa, 19, Universidade Federal do Ceará, Edições UFC, Fortaleza, 2000.

Boyd,C. E. Guiding principles for responsible aquaculture - Codes of practice. Global Aquaculture Alliance, 36 p., St. Louis, 1998.

Boyd, C. E. \& Green, B. W. Coastal water quality monitoring in shrimp farming areas. An example from Honduras. Report prepared under the World Bank, NACA, WWF and FAO Consortium Program on Shrimp Farming and the Environment. Work Progress for Public Discussion. Publish by the Consortium, 31 p., 2002.

Brasil/DPA. Plataforma tecnológica do camarão marinho cultivado. Ministério da Agricultura, Pecuária e Abastecimento/DepartamentodePesca e Aquicultura, 276 p., Brasília, 2001.

Brock, J. A.; Gose, R.; Lightner, D. V. \& Hasson, K. An overview on taura syndrome, an important disease offarmed Penaeus vannamei. Proceedings of a Special Session on Shrimp Farming, Baton Rouge, p. 84 - 94, 1995.

Bueno, S. L. S. Doenças em camarões marinhos no Brasil. Panorama da Aqüicultura, Rio de Janeiro, v. 1, n.8, p. 1-8, 1991.

Bueno, S. L. S.; Nascimento, R. M. \& Nascimento, I. Registros de infecções causadas por Baculovirus penaei em espécies nativas de camarões marinhos no Brasil. Uma revisão sobre o tema. Anais do III Simpósio Brasileiro sobre Cultivo de Camarão, V. 1, p. 357 - 372, 1989.

Bueno, S. L. S.; Nascimento, R. \& Nascimento, I. Baculovirus penaei infection in Penaeus subtilis: A new host and a new geographic range of the disease. J. World Aquac. Soc., Baton Rouge, v. 21, p. 235-237, 1990.

Farfate,I.P \& Kensley, B. Penaeoid and sergertoid shrimps and prawns of the world. Keys and diagnoses for the families and genera. Editions du Muséum National d'Histoire Naturelle, 233 pp., Paris, 1997.

Gesteira,T.C.V.\&Andrade,T.P.Registrodeocorrência de algumas enfermidades em um cultivo do camarão Litopenaeus vannamei (Boone, 1931) no Estado do Ceará. Resumos do Congresso Brasileiro sobre Crustáceos, Sociedade Brasileira de Carcinologia, São Pedro, p. 51, 2002.
Guerrelhas, A.C. B. Shrimp hatchery development in Brasil. Successful history of seedstock production. Global Aquaculture, St. Louis, v. 6, n.2, p. 67-70, 2003. Hasson, K. W.; Lightner, D. V.; Mari, J.; Bonami, J. R.; Poulos, B. T.; Mohney, L. L.; Redman, R. M. \& Brock, J.A. The geographic distribution of Taura Syndrome Virus (TSV) in the Americas: determination by histopathology and in situ hybridization using TSV specific cDNA probes. Aquaculture, Amsterdan, v.171, p. 13-26, 1999.

Kjerfve, B. \& Lacerda, L. D. Mangroves of Brazil, p. 245-272, in Lacerda, L. D. (ed.), Conservation and sustainable utilization of mangrove forests in Latin America. Mangrove Ecosystems Technical Reports, ISME, p. 245 - 272, Okinawa, 1993.

Lightner, D. V. A handbook of shrimp pathology and diagnostic procedures for diseases of cultured penaeid shrimp. The World Aquaculture Society, Baton Rouge, 1996.

Lightner, D.V.\& Redman, R. M.Penaeid virus disease of shrimp culture industry of the Americas, p. 569 588, in Fast, W.G. \& Laster, L.J. (eds.), Culture of marine shrimp: Principles and practices. Elsevier, Amsterdam, 1992.

Maia, E. P.; Correia, E. S.; Bologna, A. S.; Oliveira, A. \&Costa, C. Two year nutrients evaluation of a recirculating marine shrimp farm in Brazil. The World Aquaculture Societey, p. 444, Salvador, 2003.

Paiva, M.P. Recursos pesqueiros estuarinos e marinhos do Brasil. Ediç̧ões UFC, 287 p., Fortaleza, 1997.

Pantoja, C. R. \& Lightner, D. V. Necrotizing hepatopancreatitis: diagnosis, distribution in shrimp. Global Aquaculture Alliance, St. Louis, v. 6, n. 4, p. 18, 2003.

Preston, N. P.; Rothlisberg, P. C.; Burford, M. A. \& Jackson, C. J. The environment management of shrimp farming in Australia. Report of the World Bank, NACA, WWF and FAO Consortium Program on Shrimp Farming and Enviroment, p. 1-9, 2001.

Rocha, I. P. \& Rodrigues, J. A carcinicultura brasileira em 2003. Revista da ABCC, Recife, n. 1, p. 30-35, 2003.

Sampaio, Y. \& Costa, E. Geração de empregos diretos e indiretos na cadeia produtiva do camarão cultivado. Revista da ABCC, Recife, n. 1, p. 60 - 64, 2003. Vieira, R. H. S. F.; Gesteira, T. C. V.; Marques, L. C.; Martins, P. C. C.; Monteiro, C. M. \& Carvalho, R. L. Vibrio spp. e suas implicações sobre larviculturas de camarões marinhos. Arq. Cien. Mar, Fortaleza, v.33, p. $107-112,2000$. 